\title{
Assessment of herbicides for selectively controlling broom (Cytisus scoparius) growing with radiata pine (Pinus radiata) in New Zealand
}

\author{
Hop Tran ${ }^{1}$, Kerry C. Harrington ${ }^{1 *}$, Alastair W. Robertson ${ }^{1}$ and Michael S. Watt ${ }^{2}$
}

\begin{abstract}
Background: Broom (Cytisus scoparius (L.) Link) is an invasive weed in many commercial radiata pine (Pinus radiata D.Don) plantations throughout New Zealand. A variety of herbicides are available to selectively control young established broom plants during the first year after planting pines, but there is little published information describing which are safest for pines and most effective as the broom grows older.

Methods: A pot experiment was conducted to assess the efficacy of six selective herbicide treatments applied at three rates (recommended (medium) rate, half (low) rate and double (high) rate) for controlling broom of various ages $(3,6,9$ and 12 months old). Five treatments involving registered herbicides were compared with fluroxypyr, which is not registered for use in radiata pine or on broom. As broom is a major competitor in plantation forestry, the adverse effects of these herbicides on 12-month-old radiata pine were also assessed.

Results: The high rate of each treatment killed all the 3-, 6-, and 9-month-old broom plants, but only the high rate of hexazinone or the clopyralid/triclopyr mixture killed the 12-month-old broom plants. In addition, the medium rate of clopyralid/triclopyr, terbuthylazine or clopyralid/triclopyr/picloram/aminopyralid killed all 3-, 6-, and 9-monthold broom plants. The remaining treatments were not completely effective (i.e. median injury rating was less than 10). All of the registered herbicides caused minimal damage to radiata pine, but the damage caused by fluroxypyr to radiata pine was considered too great to recommend operational use of this chemical on its own.

Conclusions: Mixtures based on clopyralid with triclopyr gave the best selective control of potted broom plants up to 12 months old. Such mixtures will also preserve grass ground covers. Although fluroxypyr is unsuitable for use by itself, it could be assessed in further work for use with clopyralid.
\end{abstract}

Keywords: Aminopyralid, Broom, Clopyralid, Fluroxypyr, Herbicide, Hexazinone, Picloram, Pinus radiata, Selectivity, Terbuthylazine, Triclopyr

\section{Background}

The most cost-effective vegetation management strategies in New Zealand forestry operations involve the use of herbicides, both during pre-plant site preparation treatments and for release during the first and second years after planting (Rolando et al. 2011a). During the forest establishment stage, residual herbicides play an

\footnotetext{
* Correspondence: K.Harrington@massey.ac.nz

${ }^{1}$ Institute of Agriculture and Environment, Massey University, Palmerston

North 4442, New Zealand

Full list of author information is available at the end of the article
}

important part in preventing the survival of weeds germinating from the seed bank (Tran et al. 2015), while selective knockdown herbicides can release the desired trees that do become established from competition with weeds (Sullivan et al. 1998).

Radiata pine (Pinus radiata D.Don) is the most important plantation species in New Zealand, occupying approximately 1.54 million ha (90\% of all plantings) (New Zealand Forest Owners Association 2013). Broom (Cytisus scoparius (L.) Link) is an invasive shrub native to Europe that is now widespread throughout the New 
Zealand plantation forestry area (Richardson 1993). Broom is one of the most common, competitive species found in association with radiata pine. In forest plantations, broom plants grow rapidly and compete vigorously with conifers during establishment. For example, Watt et al. (2003) found that radiata pine trees growing at a dryland site without broom had an above-ground biomass 25 -fold greater than that of trees growing with broom at the end of the second year after planting. This creates a window of opportunity for forest managers to influence the long-term productivity of the crop (Watt et al. 2007). Broom produces abundant seeds that can remain dormant for many years in the soil (Bossard and Rejmánek 1994; Peterson and Prasad 1998), which makes it difficult to control without repeated applications of herbicides. Jarvis et al. (2006) estimated that the forestry industry in New Zealand treats about 5000 ha of broom each year, and this is probably still occurring.

Several herbicides are currently registered in $\mathrm{New}$ Zealand for selectively controlling seedling broom within radiata pine plantations after planting (Young 2015). Terbuthylazine and hexazinone are both triazine herbicides that can be applied to soil and foliage to control many herbaceous and woody broad-leaved weeds as well as grass species in New Zealand radiata pine forests (Rolando et al. 2013). If applied to soil, they are readily absorbed by roots and are translocated upwards in the apoplast but are less readily translocated out of leaves when applied to the foliage (Donald 1986). Terbuthylazine and hexazinone are widely applied in the forestry sector due to a lack of radiata pine phytotoxicity (when applied at their recommended rates), as well as their residual herbicidal activity, which provides weed control for up to 1 year after application (Rolando et al. 2011b). Hexazinone applied operationally to foliage and soil in spring soon after planting has resulted in limited conifer phytotoxicity in the Pacific Northwest (USA) (Ketchum and Rose 2003) but can cause phytotoxicity if trees are under stress due to disease, transplant shock or inclement weather (Young 2015) or if rates are too high (Preest 1986).

The pyridine herbicides clopyralid, picloram and triclopyr are also used for the selective control of broom in radiata pine forests within New Zealand (Rolando et al. 2013). These herbicides are absorbed by the roots and foliage of broad-leaved weed species and translocated to the site of action in actively growing meristems where they act as synthetic auxins, inhibiting the growth of plant tissues (Donald 1986). A commercial mixture of clopyralid and picloram is sold in New Zealand for the suppression of actively growing 10-50$\mathrm{cm}$-tall broom plants in young radiata pine stands, though some temporary phytotoxicity to pine trees may occur (Young 2015). Likewise, triclopyr can also be used to suppress broom growth and is safe for radiata pine if applied during dormancy at $1.8 \mathrm{~kg}$ acid equivalent (ae) ha ${ }^{-1}$ (Saville 1989), although temporary phytotoxicity can occur in trees when applied in the first year after planting at $0.6-1.2 \mathrm{~kg}$ ae $\mathrm{ha}^{-1}$ (Young 2015). Symptoms of herbicide injury to pine trees from pyridine herbicides include epinasty or curling and twisting of needles and stems followed by necrosis in severe cases (Donald 1986).

Triclopyr $\left(0.15 \mathrm{~kg}\right.$ ae $\left.\mathrm{ha}^{-1}\right)$ is also used in combination with clopyralid $\left(1.5 \mathrm{~kg}\right.$ ae $\left.\mathrm{ha}^{-1}\right)$ and picloram $\left(0.05 \mathrm{~kg}\right.$ ae ha $\left.{ }^{-1}\right)$ by some New Zealand forest managers to control broom (Rolando et al. 2013), although little published research could be found related to pine phytotoxicity or efficacy for controlling broom using this combination of herbicides (Rolando et al. 2011b).

Aminopyralid is another pyridine herbicide sold in New Zealand that has been added to combinations of triclopyr and picloram for control of brush weeds (Young 2015). Some use has been made of this mixture for the selective control of broom in young radiata pine plantations by some forest managers despite no label recommendation for this. However, low rates of aminopyralid can cause minor phytotoxicity in ponderosa pine (Pinus ponderosa Douglas ex P. Lawson and C. Lawson) in the USA (Wallace et al. 2012).

Another pyridine herbicide available in New Zealand, and very similar in structure to triclopyr, is fluroxypyr. Although it is not registered in New Zealand for control of broom or use in pines (Young 2015), Cole and Newton (1988) found it less phytotoxic to ponderosa pine than triclopyr, while providing effective control of some weedy shrub species. Thompson (1988) obtained $88 \%$ control of broom when fluroxypyr was applied at $0.40 \mathrm{~kg}$ ae ha ${ }^{-1}$ in Austrian pine (Pinus nigra Arnold).

Almost no published trial data are available, although label recommendations do exist regarding how these herbicides could be used to control broom seedlings among radiata pine. Ambiguity also exists with regard to terms such as "suppression" when used for describing these treatments, casting doubt over the adequacy of control, and warnings about possible tree damage made it difficult to determine levels of phytotoxicity, if any. Thus, the first objective of this research was to determine whether fluroxypyr or various combinations of clopyralid, triclopyr, picloram and aminopyralid would provide effective control of broom at four ages $(3,6,9$ or 12 months old). Each herbicide treatment was applied at three application rates to quantify herbicide efficacy across a dosage range. The second objective was to determine the phytotoxicity of each of these herbicide treatments/rates to 12 -month-old radiata pine plants. 


\section{Methods}

General propagation methods for broom and radiata pine Broom seeds were collected on 5 November 2007 from soil and litter beneath mature broom shrubs near Massey University, Palmerston North (40 $\left.23^{\prime} \mathrm{S}, 175^{\circ} 37^{\prime} \mathrm{E}\right)$. Seeds were extracted from the soil using wet sieving; the extracted seeds were laid out on filter paper overnight to dry and then stored in paper bags at $5{ }^{\circ} \mathrm{C}$. Four cohorts of broom seedlings were subsequently germinated at 3month intervals (22 December 2007, 23 March 2008, 26 June 2008 and 23 September 2008) to give four age cohorts $(3,6,9,12$ months) on the day of herbicide application. The hard coat of each broom seed was scarified prior to sowing by abrading the seed coat with a sharp scalpel, and these were then sown $1 \mathrm{~cm}$ deep in a seed tray containing potting mix. The trays were kept in a heated glasshouse and watered regularly.

Once broom seedlings had emerged, attained their first true leaves and were about $10 \mathrm{~cm}$ tall, 100 healthy seedlings were transplanted individually into $1.2-\mathrm{L}$ potting bags ( $9 \mathrm{~cm}$ diameter $\times 20 \mathrm{~cm}$ deep), filled with potting mix (based on $50 \%$ bark, $30 \%$ coconut husk fibre, $20 \%$ pumice (7-mm diameter) containing the slow-release fertiliser Osmocote ${ }^{\oplus}$ ). The four cohorts of broom seedlings were then kept in an unheated shade house at the Plant Growth Unit, Massey University, and the potting mix kept moist by rainfall and/or irrigation until the oldest cohort of broom was 12 months old and the youngest cohort was 3 months old.

To test for phytotoxicity of herbicide treatments on 1-year-old radiata pine, on 18 September 2008 (3 months prior to the application of herbicide treatments), 150 radiata pine plants (9 months old) were obtained from a nursery and planted into the same type of potting bags and potting mix as the broom seedlings and were then grown alongside the broom plants.

\section{Experimental design}

The experiment consisted of 19 treatments (6 herbicides $\times 3$ rates and an untreated control), applied on the same day to five cohorts of plants (four cohorts of broom at different ages and the radiata pine plants) using a randomised block design with five replicates (blocks) per treatment. The three rates represented the current recommended rate (or the rate estimated to give optimal control of broom selectively in pines if no rates were recommended), half the rate and double the rate (Table 1). These rates have been abbreviated as $M$ (medium), L (low) and $\mathrm{H}$ (high), respectively. Individual broom and radiata pine plants in pots were treated as experimental units, resulting in 380 pots for broom (19 treatments $\times 4$ cohorts; replicated five times) and 95 pots for radiata pine (19 treatments replicated five times).
The initial height of each broom and radiata pine plant was measured and recorded 1 day before the application of herbicides (Table 2). Height $(\mathrm{cm})$ was measured from the potting mix surface to the apex of the plant. The health and general condition of each broom and radiata pine plant was also assessed the same day using a scoring system ranging from 0 to 10 (where $0=$ very healthy and $10=$ very unhealthy), and this was used to allocate plants to blocks. As plants were reasonably uniform and healthy when treated, most had a score of 0,1 or 2 with differences between these mainly involving slight discolouration of some leaves due to minor nutrient deficiencies. Those plants with higher scores were not used in the trial.

The herbicide treatments were applied on 18 December 2008 using a precision gas-powered sprayer at a rate equivalent to $300 \mathrm{~L} \mathrm{ha}^{-1}$. All herbicide treatments included an organosilicone surfactant (Boost Penetrant at $0.5 \mathrm{~L} \mathrm{ha}^{-1}$ ) apart from the hexazinone (which has a label recommendation to avoid surfactants when applied to the foliage of pine trees (Young 2015)). After treatment, all broom and radiata pine plants were returned to the shade house and were irrigated regularly until the end of the trial (179 days after treatment (DAT)). The average daily temperature for the 2 weeks following spraying was $17.6{ }^{\circ} \mathrm{C}$.

\section{Assessment of herbicide effects}

The phytotoxic effects of herbicide treatments on broom and radiata pine plants were quantified using a visual rating system based on the severity of plant necrosis and other symptoms, such as chlorosis, stunting, twisting of shoots and deformation of leaves. The score for each plant ranged from 0 to $10(0$, no symptoms (healthy); 1-3, slight; 4-6, moderate; 7-9, severe; and 10, dead) at two weekly intervals until 179 DAT. The results are presented as a median of these individual scores, representing the majority of plants. Thus, a score of 5 signifies that the majority of plants had moderate necrosis rather than half of the plants were dead, and a score of 10 signifies that the majority of the plants had died rather than all the plants were dead. This rating system considered the damage across the complete plant, though slight phytotoxicity might have involved damage to just some parts of the plants such as shoot tips. Shoot height and stem diameter were also measured 113 and 179 DAT (equivalent to 3.8 and 6.0 months, respectively, after treatment). At the end of the experiment in June 2009, all the broom and pine plants (including dead plants) were cut at the base of their stems and oven dried to a constant mass at $80{ }^{\circ} \mathrm{C}$ and their dry weights were recorded. 
Table 1 Herbicide treatments used in the trial

\begin{tabular}{|c|c|c|c|}
\hline Treatment code & Active ingredient (rate, $\mathrm{kg}$ ai ha ${ }^{-1}$ or kg ae ha ${ }^{-1}$ ) & Trade name $^{\mathrm{b}}$ (rate) & $\operatorname{Cost}^{a}\left(\mathrm{NZ} \$ \mathrm{ha}^{-1}\right)$ \\
\hline clo/pic-L & Clopyralid/picloram $(0.225 / 0.15)$ & Radiate $\left(1.0 \mathrm{~L} \mathrm{ha}^{-1}\right)$ & 116 \\
\hline clo/pic-M & Clopyralid/picloram (0.45/0.3) & Radiate $\left(2.0 \mathrm{~L} \mathrm{ha}^{-1}\right)$ & 220 \\
\hline clo/pic-H & Clopyralid/picloram (0.9/0.6) & Radiate $\left(4.0 \mathrm{~L} \mathrm{ha} \mathrm{L}^{-1}\right)$ & 428 \\
\hline clo/tric-L & Clopyralid/triclopyr (0.75/0.15) & Versatill/Grazon (2.5/0.25 L ha $\left.{ }^{-1}\right)$ & 146 \\
\hline clo/tric-M & Clopyralid/triclopyr (1.5/0.3) & Versatill/Grazon (5.0/0.5 L ha $\left.{ }^{-1}\right)$ & 280 \\
\hline $\mathrm{Clo/tric-H}$ & Clopyralid/triclopyr (3.0/0.6) & Versatill/Grazon (10.0/1.0 L ha $\left.{ }^{-1}\right)$ & 548 \\
\hline cpat-L & $\begin{array}{l}\text { Clopyralid/triclopyr/picloram/aminopyralid } \\
(0.75 / 0.075 / 0.025 / 0.002)\end{array}$ & Versatill/Tordon Brushkiller XT (2.5/0.25 L ha $\left.{ }^{-1}\right)$ & 146 \\
\hline cpat-M & $\begin{array}{l}\text { Clopyralid/triclopyr/picloram/aminopyralid } \\
(1.5 / 0.15 / 0.05 / 0.004)\end{array}$ & Versatill/Tordon Brushkiller XT (5.0/0.5 L ha $\left.{ }^{-1}\right)$ & 279 \\
\hline cpat-H & $\begin{array}{l}\text { Clopyralid/triclopyr/picloram/aminopyralid } \\
(3.0 / 0.3 / 0.1 / 0.008)\end{array}$ & Versatill/Tordon Brushkiller XT (10.0/1.0 L ha $\left.{ }^{-1}\right)$ & 545 \\
\hline fluro-L & Fluroxypyr (0.25) & Starane $\left(1.25 \mathrm{~L} \mathrm{ha}^{-1}\right)$ & 64 \\
\hline fluro-M & Fluroxypyr (0.5) & Starane $\left(2.5 \mathrm{~L} \mathrm{ha}^{-1}\right)$ & 115 \\
\hline fluro- $\mathrm{H}$ & Fluroxypyr (1.0) & Starane $\left(5.0 \mathrm{~L} \mathrm{ha}^{-1}\right)$ & 218 \\
\hline terbu-L & Terbuthylazine (5.0) & Gardoprim (10 L ha $\left.{ }^{-1}\right)$ & 116 \\
\hline terbu-M & Terbuthylazine (10.0) & Gardoprim $\left(20 \mathrm{~L} \mathrm{ha}^{-1}\right)$ & 220 \\
\hline terbu-H & Terbuthylazine (20.0) & Gardoprim (40 L ha $\left.{ }^{-1}\right)$ & 428 \\
\hline hexa-L & Hexazinone (3.0) & Velpar DF (4 kg ha $\left.{ }^{-1}\right)$ & 490 \\
\hline hexa-M & Hexazinone (6.0) & Velpar DF $\left(8 \mathrm{~kg} \mathrm{ha}^{-1}\right)$ & 980 \\
\hline hexa-H & Hexazinone (12.0) & Velpar DF (16 kg ha $\left.{ }^{-1}\right)$ & 1960 \\
\hline Untreated & Untreated control & NA & \\
\hline
\end{tabular}

All herbicides apart from hexazinone were applied with organosilicone surfactant $\left(0.5 \mathrm{~L} \mathrm{ha}{ }^{-1}\right.$ Boost Penetrant)

${ }^{a}$ Costs are exclusive of tax, including cost of surfactant and are based on prices from Askin and Askin (2014)

${ }^{b}$ Manufacturers of the products were Dow AgroSciences (NZ) Ltd (Radiate, Versatill, Grazon, Tordon Brushkiller XT, Starane, Boost Penetrant), Orion Crop Protection Ltd (Gardoprim 500) and DuPont (NZ) Ltd (Velpar DF)

\section{Cost data}

The cost of each treatment is exclusive of tax but includes the cost of surfactant where used (Askin and Askin 2014).

\section{Data analysis}

All statistical analyses were conducted using SAS 9.2 software (SAS Institute Inc. 2008). Treatment effects were considered significant at $P<0.05$ for all analyses.

Table 2 Minimum, maximum and mean initial height and general condition scores of broom and radiata pine plants before treatment

\begin{tabular}{|c|c|c|c|c|c|}
\hline \multirow[t]{2}{*}{ Species } & \multirow{2}{*}{$\begin{array}{l}\text { Age } \\
\text { (months) }\end{array}$} & \multicolumn{3}{|l|}{ Height $(\mathrm{cm})$} & \multirow{2}{*}{$\begin{array}{l}\text { Condition } \\
\text { score }\end{array}$} \\
\hline & & Mean (SE) & Minimum & Maximum & \\
\hline \multirow[t]{4}{*}{ Broom } & 3 & $14.8(0.4)$ & 6.5 & 28.0 & 2.0 \\
\hline & 6 & $36.7(0.7)$ & 21.0 & 52.0 & 1.3 \\
\hline & 9 & $61.7(0.8)$ & 45.0 & 87.0 & 1.2 \\
\hline & 12 & $111.7(2.4)$ & 59.0 & 174.0 & 2.0 \\
\hline Radiata pine & 12 & $42.7(0.3)$ & 35.0 & 53.0 & 0.9 \\
\hline
\end{tabular}

Figures in brackets are standard errors of the mean. Condition scores ranged from 0 (very healthy) to 10 (very unhealthy)
Separate analyses were undertaken for each broom cohort. The injury data were on an ordinal scale so they did not meet the assumptions of normal standard parametric methods; therefore, the median ratings and mean ranks of these ratings were used to analyse the injury data collected at the end of the experiment (179 DAT). The data were analysed as a one-way analysis of variance (ANOVA) with median ratings calculated using the PROC TABULATE function and mean ranks found using the PROC MIXED function. Tukey's honestly significant difference (HSD) tests were used to perform multiple comparisons between all pairs of treatments when ANOVA results indicated significant treatment effects.

Biomass data were also analysed separately for each cohort except the 3-month-old broom. This exception occurred because some plants in the 3-month-old broom cohort had died early within the experimental period and had detached then blown away in the wind by the time the biomass data were collected. The biomass data of the 6-, 9- and 12-month-old broom were analysed with the PROC MIXED function using the restricted maximum likelihood estimation method that can handle data sets with missing data. To improve the statistical precision, 
analysis of covariance (ANCOVA) was first performed using untransformed biomass data with initial heights used as a covariate to adjust for variation among experimental units (individual plants) within each block (Harrison and Regnier 1990; Littell et al. 2006). The data were analysed first by testing a slope-equal-to-zero hypothesis to determine if covariates were needed in the model. As the analysis showed that covariates would not improve precision, they were not used. Normality of residuals were checked using the PROC UNIVARIATE function, and as preliminary results were not normally distributed, the biomass data were $\log (x+0.5)$ transformed to stabilise the variance before being analysed (Yamamura 1999) using the same procedure as above. Tukey's HSD tests were then used to perform multiple comparisons between all pairs of treatments when ANOVA results indicated significant treatment effects.

For radiata pine, the phytotoxic effects of herbicides were evaluated by using injury data collected at three dates (15, 98 and 179 DAT). These data were analysed separately using medians and mean ranks of ratings as described above for broom cohorts as the data were correlated over the course of the experiment. The radiata pine biomass data were analysed as described for the broom data.

\section{Results}

\section{Treatment costs}

The cost of each of the treatments used is shown in Table 1. Fluroxypyr was the cheapest at each of the rates used, and hexazinone was the most expensive.

\section{Effects of herbicides on broom plants}

There were significant differences in phytotoxicity (measured as median injury rating) among both the different herbicide treatments and the rates of application within each of the four age cohorts of broom (3-month broom cohort, $F_{8.23,33.7}=14.85, P<0.0001$; 6 -month broom cohort, $F_{8.6,35.2}=7.37, P<0.0001$; 9-month broom cohort, $F_{5.15,20.9}=11.61, \quad P<0.0001 ; 12$-month broom cohort, $F_{11.1,45.6}=14.28, P<0.0001$, Table 3). However, for most herbicide treatments, the application rate had more impact on injury rating than the age of broom when treated, and no interaction was found between the application rate and the age of broom (Table 4).

Median injury ratings for recommended (M) rates of the herbicides show that broom plants treated when 3, 6 or 9 months old were killed by the clopyralid/triclopyr mixture, the clopyralid/triclopyr/picloram/aminopyralid mixture and terbuthylazine (Table 3 ). The medium rate for the clopyralid/picloram mix killed all 6- and 9month-old broom plants, but did not kill all 3-monthold or 12-month-old plants. Hexazinone at $6 \mathrm{~kg}$ ai ha ${ }^{-1}$ (M) killed all broom only when applied to plants at 3 or
Table 3 Median injury rating and mean rank $\left(\bar{R}_{i j}\right)$ for treatment injury ratings 179 days after treatment of broom at 3, 6, 9 and 12 months of age

\begin{tabular}{|c|c|c|c|c|c|c|c|c|}
\hline \multirow[t]{2}{*}{ Treatment } & \multicolumn{4}{|c|}{$\begin{array}{l}\text { Median injury } \\
\text { rating (month) }\end{array}$} & \multicolumn{4}{|c|}{ Mean rank $\left(\bar{R}_{i j}\right)$ (month) } \\
\hline & 3 & 6 & 9 & 12 & 3 & 6 & 9 & 12 \\
\hline & 7 & 7 & 9 & 8 & $33.3 \mathrm{bc}$ & $24.4 b c$ & $44.0 \mathrm{abc}$ & $53.7 \mathrm{bc}$ \\
\hline o/pic-M & 9 & 10 & 10 & 7 & $48.1 \mathrm{abc}$ & $51.2 \mathrm{ab}$ & $52.8 \mathrm{abc}$ & $50.1 \mathrm{bc}$ \\
\hline o/pic-H & 10 & 10 & 10 & 9 & $67.0 \mathrm{a}$ & $52.2 \mathrm{ab}$ & $66.0 \mathrm{a}$ & $70.9 \mathrm{ab}$ \\
\hline D/tric-L & 6 & 10 & 10 & 7 & $31.4 \mathrm{bc}$ & $58.6 \mathrm{ab}$ & $51.4 a b c$ & $56.8 \mathrm{bc}$ \\
\hline o/tric-M & 10 & 10 & 10 & 9 & $52.8 \mathrm{abc}$ & $66.0 \mathrm{a}$ & $66.0 \mathrm{a}$ & $76.8 \mathrm{ab}$ \\
\hline o/tric-H & 10 & 10 & 10 & 10 & $51.9 \mathrm{abc}$ & $66.0 \mathrm{a}$ & $66.0 \mathrm{a}$ & $83.6 \mathrm{a}$ \\
\hline pat-L & 10 & 9 & 9 & 8 & $59.1 \mathrm{ab}$ & $45.8 \mathrm{abc}$ & $46.2 \mathrm{abc}$ & $58.1 \mathrm{bc}$ \\
\hline pat-M & 10 & 10 & 10 & 9 & $60.7 \mathrm{ab}$ & $59.6 \mathrm{ab}$ & $66.0 \mathrm{a}$ & $72.1 \mathrm{ab}$ \\
\hline bat-H & 10 & 10 & 10 & 9 & $67.0 \mathrm{a}$ & $66.0 \mathrm{a}$ & $66.0 \mathrm{a}$ & $73.4 \mathrm{ab}$ \\
\hline uro-L & 3 & 4 & 5 & 5 & $14.8 \mathrm{bcd}$ & $16.1 \mathrm{bc}$ & $16.9 \mathrm{bc}$ & $31.8 \mathrm{~cd}$ \\
\hline fluro-M & 3 & 6 & 5 & 5 & $19.2 \mathrm{bcd}$ & $28.8 \mathrm{abc}$ & 21.2 bc & $26.2 \mathrm{~cd}$ \\
\hline uro-H & 10 & 10 & 10 & 8 & $67.0 \mathrm{a}$ & $47.2 \mathrm{abc}$ & $66.0 \mathrm{a}$ & $57.1 \mathrm{bc}$ \\
\hline terbu-L & 10 & 10 & 5 & 3 & $67.0 \mathrm{a}$ & $54.0 \mathrm{ab}$ & 31.4 bc & $16.7 d$ \\
\hline erbu-M & 10 & 10 & 10 & 4 & $67.0 \mathrm{a}$ & $66.0 \mathrm{a}$ & $66.0 \mathrm{a}$ & $21.4 d$ \\
\hline erbu-H & 10 & 10 & 10 & 6 & $67.0 \mathrm{a}$ & $66.0 \mathrm{a}$ & $66.0 \mathrm{a}$ & $44.6 \mathrm{bcc}$ \\
\hline hexa-L & 2 & 1 & 1 & 3 & 11.3 bcde & $6.0 \mathrm{~d}$ & 9.4 bc & $9.9 \mathrm{~d}$ \\
\hline hexa-M & 10 & 10 & 1 & 3 & $57.2 \mathrm{abc}$ & $54.0 \mathrm{ab}$ & 29.8 bc & $21.9 \mathrm{~cd}$ \\
\hline hexa-H & 10 & 10 & 10 & 10 & $67.0 \mathrm{a}$ & $66.0 \mathrm{a}$ & $66.0 \mathrm{a}$ & $75.6 \mathrm{ab}$ \\
\hline Untreated & 0 & 1 & 1 & 3 & $3.2 \mathrm{e}$ & $18.1 \mathrm{bc}$ & $12.2 b c$ & $11.3 d$ \\
\hline
\end{tabular}

Median injury rating: 0 , no symptoms (healthy); $1-3$, slight; 4-6, moderate, 7-9, severe; and 10, dead. Mean rank differences apply to broom within each age cohort only, and those with the same letters are not significantly different at $a=0.05$

6 months of age and was ineffective on older seedlings, although an application rate of $12 \mathrm{~kg}$ ai ha ${ }^{-1}(\mathrm{H})$ killed all plants for all four age cohorts. There is no rate currently recommended for fluroxypyr, but the $1.0 \mathrm{~kg}$ ai ha ${ }^{-1}(\mathrm{H})$ application did kill all 3-, 6- and 9month-old plants although the $0.5 \mathrm{~kg}$ ai ha ${ }^{-1}(\mathrm{M})$ and $0.25 \mathrm{~kg}$ ai ha ${ }^{-1}(\mathrm{~L})$ rates were less effective.

When treated at 12 months old, only the high $(\mathrm{H})$ rate of hexazinone and clopyralid/triclopyr mix killed all the plants (Table 3). For recommended (M) rates, the clopyralid/triclopyr mix and the clopyralid/triclopyr/picloram/aminopyralid mix had the highest median injury rating (both 9) and highest mean ranks (76.8 and 72.1 , respectively).

Analysis of the biomass data for broom plants showed similar trends to the ranking data. For the 3-month-old broom cohort, all herbicide treatments resulted in a significant reduction in broom biomass compared with that of the untreated control treatment (Fig. 1a). Analysis of variance for the biomass of 6-, 9- and 12-month cohorts showed there was a significant effect of herbicide 
Table 4 Effect of plant age at treatment, herbicide rates and their interactions on injury ratings of broom 179 days after treatment

\begin{tabular}{|c|c|c|c|c|c|c|}
\hline \multirow[t]{2}{*}{ Herbicide code } & \multicolumn{2}{|l|}{ Age } & \multicolumn{2}{|l|}{ Rate } & \multicolumn{2}{|l|}{ Age $\times$ rate } \\
\hline & ${ }^{\mathrm{a} F}$ & $P$ & $\bar{F}$ & $P$ & $F$ & $P$ \\
\hline Clo/pic & $2.29_{(2.21,9.26)}$ & 0.1536 & $22.80_{(2.72,9.26)}$ & 0.0002 & $0.88_{(4.7,9.26)}$ & 0.5228 \\
\hline Clo/tric & $5.86_{(2.61,6.56)}$ & 0.0302 & $24.11_{(2.87,6.56)}$ & 0.0007 & $0.72_{(4.39,6.56)}$ & 0.6149 \\
\hline Cpat & $2.87_{(2.4,4.65)}$ & 0.1527 & $23.92_{(2.3,4.65)}$ & 0.0033 & $1.04_{(3.38,4.65)}$ & 0.4646 \\
\hline Fluro & $2.23_{(2.11,8.46)}$ & 0.1658 & $17.65_{(2.29,8.46)}$ & 0.0008 & $1.11_{(4.31,8.46)}$ & 0.4157 \\
\hline Terbu & $2.96_{(2.4,4.75)}$ & 0.1442 & $8.70_{(2.1,4.75)}$ & 0.0254 & $1.05_{(3.83,4.75)}$ & 0.4673 \\
\hline Hexa & $1.04_{(2.2,10)}$ & 0.3937 & $19.01_{(2.51,10)}$ & 0.0003 & $1.58_{(4.75,10)}$ & 0.2518 \\
\hline
\end{tabular}

${ }^{\mathrm{a}} \mathrm{F}$ test with degrees of freedom in brackets. Values in italics indicate statistically significant effects at $P<0.05$

treatment (6-month broom cohort, $F_{18,56.7}=8.32, P<$ 0.0001 ; 9-month broom cohort, $F_{18,68.1}=9.80, P<0.0001$; 12-month broom cohort, $\quad F_{18,72}=6.20, \quad P<0.0001$ ) (Fig. 1b-d). However, all three rates of application of the clopyralid/triclopyr/picloram/aminopyralid mix resulted in the biomass of broom, treated when 12 months old, being similar to that obtained by treatments that killed all plants.

\section{Effects of herbicides on radiata pine}

The analysis of mean ranks for the rating of phytotoxicity in radiata pine plants showed no significant differences between treatments, although the high rate of hexazinone and the two higher rates of fluroxypyr did cause the expression of some phytotoxicity to occur at 98 and 179 DAT (Table 5). Phytotoxicity caused by the fluroxypyr mainly involved twisting of stems and necrosis of stem tips.

Analysis of covariance on biomass using the initial height $\left(F_{1,4.1}=19.84, P=0.0106\right)$ showed that treatments were significantly different $\left(F_{18,71.9}=2.17, \quad P=0.0111\right)$ (Fig. 1e). The biomass of radiata pine treated with the high rate of hexazinone and high rate of fluroxypyr was lower than radiata pine in most other treatments (Fig. 1e).

\section{Discussion}

A recent survey by Rolando et al. (2013) found that New Zealand forest managers are currently using either aerial application or spraying in patches around each radiata pine tree (spot treatment) to release radiata pine from weed competition in the first year after planting. This operation is usually undertaken during September to December following a winter planting. Most managers conduct a second control operation 1 to 4 years after planting, with regrowth of broom often the reason for this second release spraying. A typical treatment for the first release spraying involves a mixture of $7.0 \mathrm{~kg}^{\mathrm{ai}} \mathrm{ha}^{-1}$ terbuthylazine and $1.8 \mathrm{~kg}$ ai ha ${ }^{-1}$ of hexazinone. This mixture was not tested in the current trial, but hexazinone was used alone at nearly double this rate $\left(3.0 \mathrm{~kg}\right.$ ai ha $\left.{ }^{-1}\right)$ and provided limited control of even the youngest (3-month-old) broom. Therefore, any control of broom from a terbuthylazine/hexazinone mixture will probably be due to the terbuthylazine component, though the possibility of synergistic effects from mixing the two herbicides cannot be discounted. Results from the present study showed that application of terbuthylazine alone at a rate of $5 \mathrm{~kg}$ ai ha ${ }^{-1}$ gave good control (median injury rating of 10) of 6-month-old broom (37 $\mathrm{cm}$ tall), although $10 \mathrm{~kg}$ ai ha ${ }^{-1}$ was required to give a similar level of control of 9-month-old broom $(62 \mathrm{~cm}$ tall). This contrasts with results obtained by Rolando et al. (2011b), in which their application of $8 \mathrm{~kg}$ ai ha ${ }^{-1}$ terbuthylazine $+2 \mathrm{~kg}$ ai ha ${ }^{-1}$ hexazinone to 4-month-old broom, varying in height from 5 to $19 \mathrm{~cm}$ grown within pots, only resulted in $40 \%$ mortality after 3 months.

Because there is a greater risk of damage to radiata pine from hexazinone than terbuthylazine, label recommendations warn not to use a surfactant with hexazinone, whereas it can be used with terbuthylazine (Young 2015). Thus, a surfactant was used with terbuthylazine in the current trial but not with hexazinone. This may explain why terbuthylazine gave better control of broom in this trial than that reported by Rolando et al. (2011b). In that trial, no surfactant was used in their treatment when terbuthylazine was used in combination with hexazinone. The improved control of broom by terbuthylazine in the current trial suggests that, where broom is the main weed targeted during release spraying, adding a surfactant to terbuthylazine may be better than adding hexazinone.

Although the highest rate of hexazinone (12 kg ai ha $\left.{ }^{-1}\right)$ did give good control of broom (median injury rating of 10 for all growth stages tested), this rate was more expensive than alternative treatments (Table 1), and lower rates did not provide adequate control for older broom (median injury rating of 3 or less for broom that was 9 and 12 months old). Also, some minor symptoms of phytotoxicity occurred to radiata pine with hexazinone at the highest rate, and these were only expressed towards the end of the trial with pine plants smaller than other plants. The lack of phytotoxicity to radiata pine at $6 \mathrm{~kg}$ ai ha ${ }^{-1}$ was expected as plants were growing actively and not under 


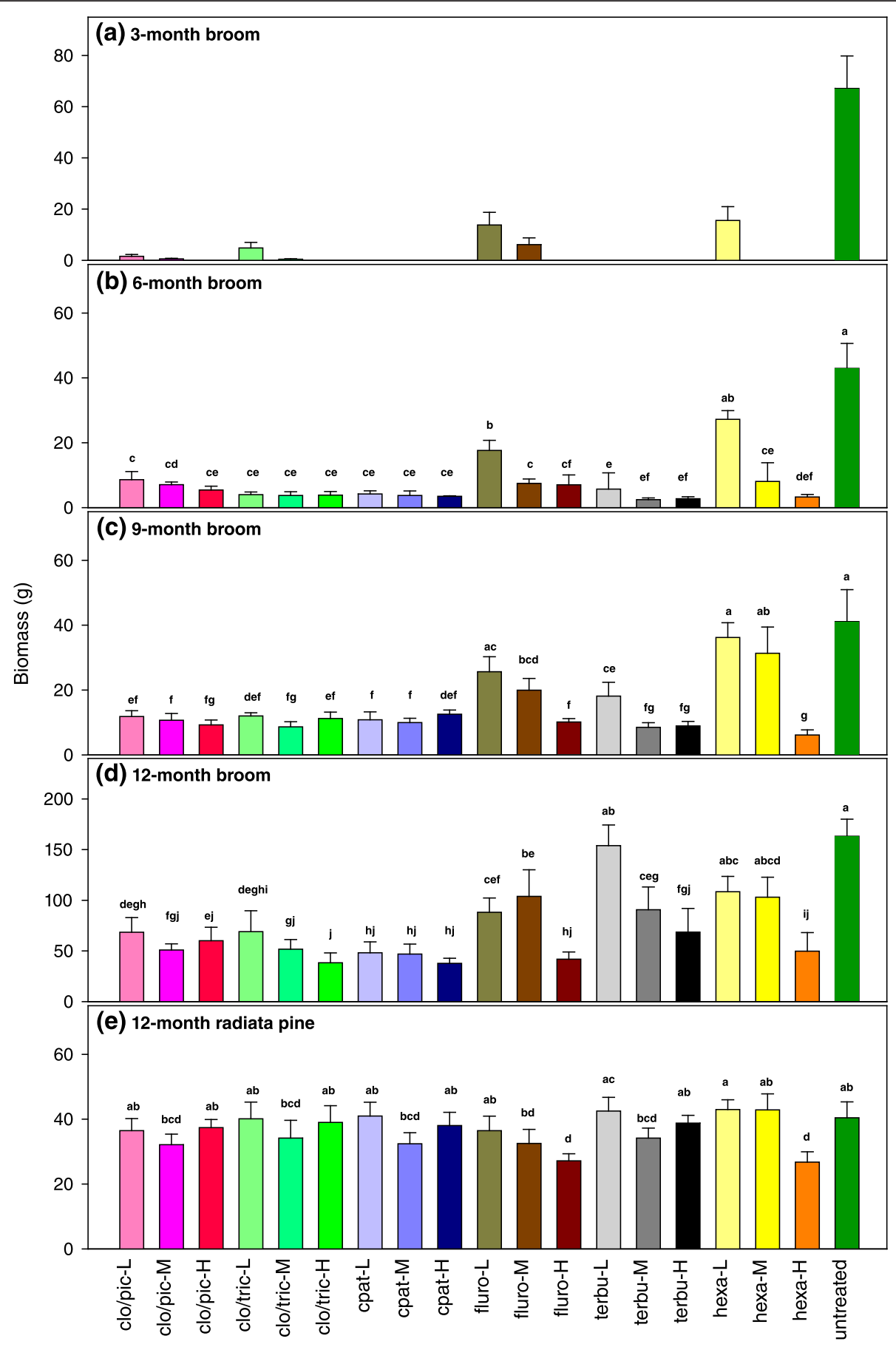

Fig. 1 Mean (with standard error of the mean) dry weight (g) of the following: a 3-month-old broom cohort (some data not collected due to death of plants); b 6-month-old broom cohort; c 9-month-old broom cohort; $\mathbf{d} 12$-month-old broom cohort; and e 12-month-old radiata pine 179 days after treatment. Means within each graph with the same letter are not significantly different at $a=0.05$

stress. However, hexazinone can cause damage if applied to trees which have poor vigour and are under stress (Young 2015).

In a survey of New Zealand forest managers, Rolando et al. (2013) found that subsequent release sprays were based on clopyralid, with the addition of picloram and/or triclopyr. The three combinations of herbicides assessed in this trial based on clopyralid gave good control of broom at all rates assessed, though the two mixtures with triclopyr were more effective than the clopyralid/picloram mixture, especially when on 12-month-old broom. The medium rate tested for the two treatments that included 
Table 5 Median injury rating and mean rank $\left(\bar{R}_{i j}\right)$ for treatment injury ratings for 12-month radiata pine 15, 98 and 179 days after treatment of 12-month-old radiata pine

\begin{tabular}{|c|c|c|c|c|c|c|}
\hline \multirow[t]{2}{*}{ Treatment } & \multicolumn{3}{|c|}{ Median injury rating (DAT) } & \multicolumn{3}{|c|}{ Mean rank $\left(\overline{\mathrm{R}}_{\mathrm{ij}}\right)(\mathrm{DAT})$} \\
\hline & 15 & 98 & 179 & 15 & 98 & 179 \\
\hline clo/pic-L & 1 & 1 & 1 & 157.3 & 157.3 & 182.1 \\
\hline clo/pic-M & 1 & 1 & 1 & 132.5 & 132.5 & 132.5 \\
\hline clo/pic-H & 1 & 1 & 1 & 132.5 & 132.5 & 157.3 \\
\hline clo/tric-L & 1 & 1 & 1 & 108.3 & 132.5 & 157.3 \\
\hline clo/tric-M & 1 & 1 & 1 & 132.5 & 132.5 & 157.3 \\
\hline Clo/tric-H & 1 & 1 & 1 & 132.5 & 133.1 & 108.3 \\
\hline cpat-L & 1 & 1 & 1 & 132.5 & 84.1 & 84.1 \\
\hline cpat-M & 1 & 1 & 1 & 132.5 & 157.3 & 182.1 \\
\hline cpat-H & 1 & 1 & 1 & 132.5 & 136.2 & 161.0 \\
\hline fluro-L & 1 & 1 & 1 & 133.1 & 157.3 & 157.3 \\
\hline fluro-M & 1 & 6 & 4 & 132.5 & 222.6 & 194.6 \\
\hline fluro-H & 1 & 5 & 2 & 157.3 & 274.9 & 216.7 \\
\hline terbu-L & 1 & 1 & 1 & 108.3 & 108.3 & 108.3 \\
\hline terbu-M & 1 & 1 & 1 & 132.5 & 157.3 & 157.3 \\
\hline terbu-H & 1 & 1 & 1 & 132.5 & 108.3 & 108.3 \\
\hline hexa-L & 1 & 1 & 1 & 108.3 & 132.5 & 132.5 \\
\hline hexa-M & 1 & 1 & 1 & 108.3 & 157.3 & 132.5 \\
\hline hexa-H & 1 & 1 & 2 & 157.3 & 182.1 & 210.0 \\
\hline Untreated & 1 & 1 & 1 & 108.3 & 133.0 & 108.3 \\
\hline
\end{tabular}

Median injury rating: 0, no symptoms (healthy); 1-3, slight; 4-6, moderate; 7-9, severe; and 10, dead

Mean ranks within each column were not significantly different at $a=0.05$

both clopyralid and triclopyr mixtures (clo/tric and cpat) (which were based on rates recommended to forestry managers) appeared similar in efficacy. Although the highest rate of the clopyralid/triclopyr mix (clo/ tric- $\mathrm{H}$ ) gave slightly better control than the medium rate of both mixes (clo/tric-M and cpat-M), the difference was not statistically significant and cost was twice the medium rates. Thus, there does not appear to be an advantage in adding picloram and aminopyralid to the clopyralid/triclopyr mix. However, the clopyralid/triclopyr/ picloram/aminopyralid mix would cost the same as the clopyralid/triclopyr mix based on the prices obtained from Askin and Askin (2014) (Table 1). Comparisons of costs will vary depending on market prices for the various forms of triclopyr and combinations available.

The medium rates of the two clopyralid/triclopyr mixtures involved application of clopyralid at a rate of $1.5 \mathrm{~kg}$ ae $\mathrm{ha}^{-1}$. The same rate of clopyralid used alone was shown by Tran et al. (2015) to have the added benefit of either preventing or severely retarding establishment of new broom seedlings for approximately 14 weeks after application. Also, the tolerance of grasses to these auxinic herbicide mixtures (Gous 2005) will allow grass ground covers to survive and increase their density, which is not the case with applications of terbuthylazine or hexazinone. This is an important factor in the choice of chemical treatment as Tran (2013) showed the importance of having competitive grass ground covers to prevent further establishment of broom from the soil seed bank.

Because fluroxypyr has no current recommendation for use with radiata pine or for control of broom (Young 2015), application rates used in this trial were based on other uses of this herbicide. The broom efficacy work showed that the medium rate selected was too low to give good control of broom (median injury ratings of only 6 or less), whereas the high rate $\left(1.0 \mathrm{~kg}\right.$ ae ha $\left.{ }^{-1}\right)$ gave very good control of broom (median injury ratings of 10 for plants 3 , 6 or 9 months old), similar to that obtained by the clopyralid/triclopyr mixtures. However, the phytotoxicity caused to radiata pine by the two higher rates of fluroxypyr showed it was not suitable for selective use in pines at these rates. This result was not surprising given the very similar nature of fluroxypyr to triclopyr, as triclopyr at $0.6 \mathrm{~kg}$ ae ha ${ }^{-1}$ was shown by Rolando et al. (2011b) to cause damage to 16-month-old radiata pine plants. In contrast, triclopyr applied at $0.6 \mathrm{~kg}_{\mathrm{ge} \mathrm{ha}}{ }^{-1}$ in the high clopyralid/triclopyr treatment in the current study did not cause the same decrease in tree growth as recorded by Rolando et al. (2011b). Fluroxypyr did not appear suitable for controlling broom selectively in radiata pine based on this experiment. However, it would be interesting to compare a clopyralid/fluroxypyr mix with a clopyralid/triclopyr mix at comparable rates to determine whether any advantage (e.g. lower cost, better efficacy) would be provided by using fluroxypyr rather than triclopyr in combination with clopyralid.

\section{Conclusions}

Clopyralid applied at a rate of $1.5 \mathrm{~kg}$ ae ha- with an organosilicone surfactant in combination with triclopyr at $0.3 \mathrm{~kg}$ ae ha ${ }^{-1}$, or with triclopyr, picloram and aminopyralid at rates of $0.15,0.05$ and $0.004 \mathrm{~kg}^{\mathrm{ae} \mathrm{ha}} \mathrm{ha}^{-1}$, respectively, gave the best control of broom across all age cohorts (3-12 months). These treatments also had no adverse effects on 12-month-old radiata pine. Fluroxypyr might be a suitable replacement for triclopyr if applied at the same rates (i.e. $0.15-0.6 \mathrm{~kg}$ ae ha ${ }^{-1}$ ), but fluroxypyr was phytotoxic to radiata pine at the rates assessed in this trial (especially at $1.0 \mathrm{~kg}$ ae ha ${ }^{-1}$ ). Terbuthylazine applied in conjunction with an organosilicone surfactant gave good control of 3-, 6- or 9-month-old broom, whereas the rates of hexazinone needed to control older broom were too expensive and caused some phytotoxicity to 12-month-old radiata pine. Further testing of the most promising treatments will need to be conducted 
under field conditions, where their effects on radiata pine and broom of different ages grown on different sites, seasons and climatic conditions can be tested.

\section{Chemical names of herbicides mentioned in text} Aminopyralid (4-amino-3,6-dichloropyridine-2-carboxyalic acid), clopyralid (3,6-dichloropyridine-2-carboxylic acid), fluroxypyr ([(4-amino-3,5-dichloro-6-fluoro-2pyridinyl)oxy]acetic acid), hexazinone (3-cyclohexyl-6dimethylamino-1-methyl-1,3,5-triazine-2,4-dione), picloram (4-amino-3,5,6-trichloro-2-pyridinecarboxylic acid), terbuthylazine (N-tert-butyl-6-chloro- $\mathrm{N}^{\prime}$-ethyl-1,3,5-triazine2,4-diamine), triclopyr ([(3,5,6-trichloro-2-pyridinyl)oxy] acetic acid).

\section{Acknowledgements}

We wish to thank the Foundation for Research, Science and Technology (FoRST) and New Zealand's International Aid and Development Agency (NZAID) for financial assistance, chemical companies for providing their products and the Plant Growth Unit (Massey University) staff for technical assistance.

\section{Authors' contributions}

HT was the primary author, conducted all measurements in the trial and analysed the data. $\mathrm{KCH}$ designed and applied the treatments and wrote parts of the paper. AWR and MSW helped with data analysis and writing. All authors read and approved the final manuscript.

\section{Competing interests}

The authors declare that they have no competing interests.

\section{Author details}

${ }^{1}$ Institute of Agriculture and Environment, Massey University, Palmerston North 4442, New Zealand. ${ }^{2}$ Scion, PO Box 29237Fendalton, Christchurch 8540, New Zealand.

Received: 18 November 2015 Accepted: 14 July 2016 Published online: 19 August 2016

\section{References}

Askin, D., \& Askin, V. (2014). Financial budget manual 2014. Lincoln: Lincoln University.

Bossard, C. C., \& Rejmánek, M. (1994). Herbivory, growth, seed production and resprouting of an exotic invasive shrub Cytisus scoparius. Biological Conservation, 67, 193-200.

Cole, E. C., \& Newton, M. (1988). Potential use of fluroxypyr alone and in mixtures for pine release. Proceedings of the Western Society of Weed Science, 41, 101-107.

Donald, D. G. M. (1986). Cleaning operations in South African forestry. South African Forestry Journal, 137(1), 38-49.

Gous, S. (2005). Herbicides. In M. Colley (Ed.), Forestry handbook (pp. 112-113). Christchurch: New Zealand Institute of Forestry Inc.

Harrison, S. K., \& Regnier, E. E. (1990). Assessing herbicide phytotoxicity with covariance analysis. Weed Technology, 4(4), 828-832

Jarvis, P. J., Fowler, S. V., Paynter, Q.. \& Syrett, P. (2006). Predicting the economic benefits and costs of introducing new biological control agents for Scotch broom Cytisus scoparius into New Zealand. Biological Control, 39, 135-146.

Ketchum, J. S., \& Rose, R. (2003). Preventing establishment of exotic shrubs (Cytisus scoparius (L.) Link. and Cytisus striatus (Hill)) with soil active herbicides (hexazinone, sulfometuron, and metsulfuron). New Forests, 25(2), 83-92.

Littell, R. C., Milliken, G. A., Stroup, W. W., Wolfinger, R. D., \& Schabenberger, O. (2006). SAS for mixed models (2nd ed.). Cary: SAS Institute Inc.

New Zealand Forest Owners Association. (2013). New Zealand plantation forest industry facts and figures. Wellington: NZFOA.

Peterson, D. J., \& Prasad, R. (1998). The biology of Canadian weeds. 109. Cytisus scoparius (L.) Link. Canadian Journal of Plant Science, 78(3), 497-504.

Preest, D. (1986). Tolerance of radiata pine to three formulations of hexazinone. Proceedings of the New Zealand Weed and Pest Control Conference, 39, 85-88.
Richardson, B. (1993). Vegetation management practices in plantation forests of Australia and New Zealand. Canadian Journal of Forest Research, 23(10), 1989-2005.

Rolando, C. A., Watt, M. S., \& Zabkiewicz, J. A. (2011a). The potential cost of environmental certification to vegetation management in plantation forests: a New Zealand case study. Canadian Journal of Forest Research, 41(5), 986-993.

Rolando, C. A.r Gous, S., \& Watt, M. S. (2011 b). Preliminary screening of herbicide mixes for the control of five major weed species on certified Pinus radiata plantations in New Zealand. New Zealand Journal of Forestry Science, 41, 165-175.

Rolando, C. A., Garrett, L. G., Baillie, B. R., \& Watt, M. S. (2013). A survey of herbicide use and a review of environmental fate in New Zealand planted forests. New Zealand Journal of Forestry Science, 43, 17

SAS Institute Inc. (2008). SAS/STAT 9.2 user's guide. Cary: SAS Institute Inc.

Saville, G. W. (1989). Field evaluation of Pinus radiata tolerance to triclopyr. Proceedings of the New Zealand Weed and Pest Control Conference, 42, 121-123.

Sullivan, T., Wagner, R., Pitt, D., Lautenschlager, R., \& Chen, D. (1998). Changes in diversity of plant and small mammal communities after herbicide application in sub-boreal spruce forest. Canadian Journal of Forest Research, 28(2), 168-177.

Thompson, A. R. (1988). Fluroxypyr, a new herbicide for shrub and woody weed control in forestry and amenity areas. Aspects of Applied Biology, 16, 177-182.

Tran, H. (2013). The ecology and integrated management of broom (Cytisus scoparius) in New Zealand plantation forests. PhD thesis, Massey University, New Zealand. http://hdl.handle.net/10179/5468. Accessed 18 Nov 2015.

Tran, H., Harrington, K. C., Robertson, A. W., \& Watt, M. S. (2015). Relative persistence of commonly used forestry herbicides for preventing the establishment of broom (Cytisus scoparius) seedlings in New Zealand plantations. New Zealand Journal of Forestry Science, 45, 6. doi:10.1186/ s40490-015-0039-6.

Wallace, J. M., Prather, T. S., \& Peterson, V. (2012). Effects of aminopyralid on ponderosa pine (Pinus ponderosa). Invasive Plant Science and Management, 5(2), 164-169.

Watt, M. S., Kimberley, M. O., Cooker, G., Richardson, B., \& Estcourt, G. (2007). Modelling the influence of weed competition on growth of young Pinus radiata. Development and parameterization of a hybrid model across an environmental gradient. Canadian Journal of Forest Research, 37, 607-616.

Watt, M. S., Whitehead, D., Mason, E. G., Richardson, B., \& Kimberley, M. O. (2003). The influence of weed competition for light and water on growth and dry matter partitioning of young Pinus radiata, at a dryland site. Forest Ecology and Management, 183, 363-376.

Yamamura, K. (1999). Transformation using $(x+0.5)$ to stabilize the variance of populations. Researches on Population Ecology, 41(3), 229-234.

Young, S. (2015). New Zealand Novachem Agrichemical Manual. Christchurch: Agrimedia Limited. www.novachem.co.nz.

\section{Submit your manuscript to a SpringerOpen ${ }^{\circ}$ journal and benefit from:}

- Convenient online submission

- Rigorous peer review

- Immediate publication on acceptance

- Open access: articles freely available online

- High visibility within the field

- Retaining the copyright to your article

Submit your next manuscript at $\boldsymbol{s p r i n g e r o p e n . c o m ~}$ 